\title{
Cardiac Rehabilitation on Health Behaviors and Clinical Outcomes among Myocardial Infarction Patients
}

\author{
Yusshy Kurnia Herliani ${ }^{1}$, Yaowarat Matchim ${ }^{2}$, Charuwan Kritpracha ${ }^{3}$ \\ ${ }^{1}$ Faculty of Nursing, Padjadjaran Univesity, Indonesia \\ ${ }^{2,3}$ Medical Nursing Department, Faculty of Nursing, Prince of Songkla University, Thailand
}

\begin{tabular}{l} 
Article Info \\
\hline Article history: \\
Received Aug 19, 2015 \\
Revised Dec 20, 2015 \\
Accepted Jan 26, 2016 \\
\hline
\end{tabular}

\section{Keyword:}

Cardiac rehabilitation Myocardial infarction Clinical outcomes Family-based self-efficacy Health behaviors

\begin{abstract}
The lack of adherence to health behaviors in cardiac rehabilitation (CR) is the leading cause of recurrent myocardial infarction (MI) in Indonesia. This randomized control trial (RCT) study was conducted to examine the effect of a family based self-efficacy enhancing cardiac rehabilitation program on selfefficacy in cardiac health behaviors, health behaviors, and clinical outcomes among MI patients in Indonesia. Sixty MI patients who met the inclusion criteria were randomized by the modified stratified-block method and assigned into either the control group or the experimental group. The patients in the experimental group received the program during phase I over two days and continued to phase II of CR with weekly follow-up sessions. Patients were asked to complete the Self-Efficacy in Cardiac Health Behaviors Scale (SECHBS) and the Modified Myocardial Infarction Health Behaviors Questionnaire (Modified MIHBQ). The results revealed that self-efficacy, health behaviors, and clinical outcomes such as fasting blood glucose, total cholesterol, LDL, triglyceride, and BMI of the patients after receiving the intervention were significantly better than before receiving the intervention, except for blood pressure, and HDL levels. Self-efficacy, health behaviors, and clinical outcomes such as total cholesterol, LDL, and triglyceride were significantly better in patients in the experimental group than those in the control group ( $\mathrm{p}<0.05)$, except for blood pressure, HDL, BMI, and blood glucose levels $(p>0.05)$. In conclusion, the family based self-efficacy enhancing cardiac rehabilitation program shows evidence of effectiveness in enhancing self-efficacy, health behaviors, and some clinical outcomes in MI patients.
\end{abstract}

Copyright @ 2016 Institute of Advanced Engineering and Science. All rights reserved.

Corresponding Author:

Yusshy Kurnia Herliani,

Faculty of Nursing,

Padjadjaran University,

Jl. Raya Bandung-Sumedang Km 21, Jatinangor, Sumedang, West Java, Indonesia.

Email: yusshy.herliani@gmail.com

\section{INTRODUCTION}

Myocardial infarction (MI) is the leading cause of death and disability worldwide [1]. More than a million people in Indonesia and approximately 227.364 people in West Java Province of Indonesia were diagnosed with coronary heart disease (CHD) in 2013 [2]. Despite the proven effectiveness of treatments, recurrent cardiac events are still the critical issue among patients with MI. About one-fifth (21.2\%) of patients were still reported to have a recurrent MI after receiving treatment [3]. Therefore, the prevention of recurrent cardiac events through cardiac rehabilitation (CR) is essential for MI patients.

Although CR has been shown to have favorable effects, only one-third of patients experiencing a cardiac event undergo CR [4]. In Indonesia, the implementation of CR is considerably underutilized due to distance from facility, socio-economic status, low or no physician referral to CR, low motivation, as well as 
insurance coverage and payment [5]. Moreover, the lack of adherence to health behaviors, which are the core components of $\mathrm{CR}$, have been identified as the leading cause of recurrent $\mathrm{MI}$ and readmission of patients to hospital in Indonesia [6]. Therefore, modifying risk factors related to improper health behaviors are important in a CR program to reduce and prevent the recurrence of a cardiac event.

Based on the American Heart Association (AHA)'s recommendations, the health behaviors that are included as core components of cardiac rehabilitation and secondary prevention are medication adherence, exercise, dietary modification, stress management, and smoking cessation [7]. Kang, Yang, and Kim [8] reported that self-efficacy was the factor with the most influence on health behaviors. Self-efficacy is an individual's confidence to successfully behave in a certain way [9]. Therefore, health behaviors of MI patients need to be promoted by manipulating self-efficacy using self-efficacy-based intervention [10].

Previous research studies have tried to provide interventions based on the self-efficacy theory [11][13]. In fact, previous studies concerned in participation in CR and hospital readmissions [12], showed insignificant results for any behaviors such as diet and smoking cessation [13], and did not investigate clinical outcomes and smoking cessation [11]. Whereas smoking was a significant risk factor for MI and death [14].

Despite the study of Ahyana [11] showed significantly positive effects, participants still reported some barriers towards dietary behaviors and medication adherence due to the eating culture in one family. Therefore, in this study, the researcher will control influencing factors and involve family in the CR program to enhance self-efficacy and health behaviors, as well as overcome the barriers. Family has a powerful influence on lessening barriers and enhancing self-efficacy [15]. Previous research proved that family participation in exercise together with patients would increase patient's confidence and lessen anxiety when compared with those whose family only observed [16].

In addition to health behaviors, the AHA recommended the control and maintenance of body weight, cholesterol, blood pressure, and blood glucose levels for patients who participate in CR program [7],[17]. Savage, Sanderson, Brown, Berra, and Ades [18] reported that clinical outcomes will provide important information to guide the treatment. Essentially, measuring clinical outcomes is a critical element for optimizing treatment in a CR program and monitoring the risk factors of a cardiac event [7]. For this reasons, this study developed and tested the effects of a family based self-efficacy program on health behaviors and clinical outcomes among MI patients.

\section{RESEARCH METHOD}

\subsection{Setting and sample}

The sample of this study was 60 patients with MI and the selected family members. MI patients were recruited from the CICU (Cardiac Intensive Care Unit) or the HCCU (High Cardiac Care Unit) of Hasan Sadikin Hospital, West Java Province, Indonesia. A family member was defined as a blood relative, spouse, or other family member who currently lived with the patient and not included family helper. The sample of MI patients was selected using the following inclusion criteria: 1) aged >18 years old; 2) have no cognitive impairment; 3) agree to participate in the study; 4) able to communicate in Indonesian language; 5) have a family member who is able to participate throughout the program; 6) live at home with family after discharge from the hospital; 7) available for a telephone follow-up and visit to the OPD; 9) have stable hemodynamic levels; and 10) have no chest pain or dyspnea. This study was conducted from October, 23 2014 to March, 102015.

\subsection{Sampling procedures}

Convenience sampling was used as the sampling procedure of this study. The patients who consented to participate in the study were randomized with the modified stratified-block method. Randomization was stratified according to gender (two levels: male, and female) and age (two levels: $\leq 65$ years old, and $>65$ years old). With these two covariates, there were four possible strata. Then, proportional allocation was conducted by calculating the percentage of each stratum from the population, and the number of sample in each stratum was calculated by using the total sample of 60 patients [19]. The number of samples and covariate between the control group and the experimental group were equal. Patients who agreed to participated in the study were identified the characteristics and allocated into one stratum that met with the characteristics. The simple randomization was then conducted in-group of each stratum to determine the participant's assignment into the experimental group or the control group by flipping the coin. When the head appeared, the patient was assigned into experimental group, while tail appeared; the patient was assigned into control group. The process was continued until all blocks were filled with the set number of samples. 


\subsection{Data analysis}

The researcher used descriptive and inferential statistics to analyze the data. Descriptive statistics was used to analyze and describe the demographic data and health information of the patients. The independent $\mathrm{t}$ - test was used to test the mean score differences between the experimental group and the control group. Accordingly, the paired $\mathrm{t}$ - test was used to test the mean score differences within the experimental group, before and after receiving the program.

\subsection{Data collection tool}

\subsubsection{Demographic data and health related questionnaire (DDHQ)}

The DDHQ consists of two components, namely the patient's information and the health related data, and the family's information and health related data. The patient's information and health related data were age, gender, BMI, marital status, level of education, monthly incomes, occupation, and number of hospitalizations, types of MI, treatment, and medication. The Family's information and health related data composed of age, gender, marital status, monthly incomes, education level, occupation, relationship with the patient, family history, experience in taking care of a patient with MI, and the level of confidence for taking care of a patient with MI.

\subsubsection{Modified myocardial infarction health behaviors questionnaire (Modified MIHBQ)}

The Modified MIHBQ is a self-reported health behaviors questionnaire that was developed by Ahyana [11] based on the American Heart Association and American Association of Cardiovascular and Pulmonary Rehabilitation. The components of modified MIHBQ consisted of five subscales of health behaviors: 1) dietary modification; 2) exercise; 3) medication adherence; 4) stress management; and 5) smoking cessation. The score was rated as $1=$ never, $2=$ sometimes, $3=$ often, and $4=$ routinely. Except the negative questions $(2,4,5,6,12,13,14,15,16,17,30,31,32,33)$, the score was reversed. The total score ranges from 34 to 136 . Higher scores indicate more frequent performance of health behaviors.

\subsubsection{Self-Efficacy in Cardiac Health Behaviors Scale (SECHBS).}

Self-efficacy was measured by the Self-Efficacy in Cardiac Health Behaviors Scale (SECHBS). The SECHBS which has five sub-scales was modified by the researcher based on the self-efficacy theory and cardiac rehabilitation guideline established by the American Heart Association (AHA) [7],[20]. The patient's self-confidence can be rated on a scale of 0 to 10 . The higher score refers to a more confident state to perform various cardiac health behaviors.

\subsubsection{Clinical outcomes parameters}

The clinical outcomes that were assessed in this study: were blood pressure (BP), blood glucose, cholesterol, and BMI. BP was measured by a mercury sphygmomanometer as recommended by the AHA. BMI was calculated by measuring the height and the weight of the patient using a digital weight scale provided by the hospital. Blood glucose and cholesterol were measured at the hospital laboratory. In order to get an accurate value of blood glucose and cholesterol levels, the patients were instructed to take nothing orally except water and medication for 12 hours before the test.

\subsection{Intervention}

This five-week program for MI patients was developed by the researcher based on the integration of the self-efficacy theory, the concept of family support and the American Heart Association's (AHA) recommendations of a CR program. The program comprised of two sessions: the in-hospital sessions and the follow-up sessions. In-hospital sessions were delivered two days and consisted of an introductory meeting with family member, and two times meetings. The activities consisted of educational and sharing session, vicarious experience video about MI patients who have had success in performing health behaviors, facilitated patients, and family to understand normal sensations and possible minor physical discomforts, demonstrated breathing for relaxation and exercise. Follow up session was undertaken weekly by telephone calls to discuss obstacles and strategies used to overcome these obstacles, followed by affirmation of the patient's efforts and successes. 
3. RESULTS

3.1. The demographic and health related characteristics of the patients

The demographic and health related characteristics of the patients presented in Table 1.

Table 1. The Differences of Patients Demographic Characteristics of the Experimental and the Control Groups $(\mathrm{N}=60)$

\begin{tabular}{|c|c|c|c|c|c|c|}
\hline \multirow[t]{2}{*}{ Characteristic } & \multicolumn{2}{|c|}{$\begin{array}{c}\text { Experimental Group } \\
(\mathrm{n}=30)\end{array}$} & \multicolumn{2}{|c|}{$\begin{array}{c}\text { Control Group } \\
(\mathrm{n}=30)\end{array}$} & \multirow{2}{*}{$\begin{array}{l}\text { Statistic } \\
\text { values }\end{array}$} & \multirow[t]{2}{*}{ p-value } \\
\hline & $\mathrm{n}$ & $\%$ & $\mathrm{n}$ & $\%$ & & \\
\hline $\begin{array}{l}\text { Age (year) } \\
\quad(\text { Min }- \text { Max })=(37-79)\end{array}$ & \multicolumn{2}{|c|}{ Mean $=56.87 \mathrm{SD}=9.65$} & \multicolumn{2}{|c|}{ Mean $=55.80 \mathrm{SD}=8.96$} & $.44^{b}$ & .659 \\
\hline Gender & & & & & $.09^{\mathrm{a}}$ & .754 \\
\hline Male & 24 & $80.0 \%$ & 23 & $76.7 \%$ & & \\
\hline Female & 6 & $20.0 \%$ & 7 & $23.3 \%$ & & \\
\hline Marital status & & & & & $.24^{\mathrm{d}}$ & $.038^{*}$ \\
\hline Married & 27 & $90.0 \%$ & 30 & $100 \%$ & & \\
\hline Widower/ Widow & 3 & $10.0 \%$ & 0 & $0.0 \%$ & & \\
\hline Educational Level & & & & & $3.50^{\mathrm{c}}$ & .478 \\
\hline No schooling & 3 & $10.0 \%$ & 2 & $6.7 \%$ & & \\
\hline Elementary school & 3 & $10.0 \%$ & 8 & $26.7 \%$ & & \\
\hline Junior high school & 5 & $16.7 \%$ & 4 & $13.3 \%$ & & \\
\hline High School & 12 & $40.0 \%$ & 12 & $40.0 \%$ & & \\
\hline College or higher & 7 & $23.3 \%$ & 4 & $13.3 \%$ & & \\
\hline Monthly expense & & & & & $3.06^{\mathrm{a}}$ & .376 \\
\hline $\begin{array}{l}<1 \text { million IDR } \\
(<76.97 \text { USD })\end{array}$ & 6 & $20.0 \%$ & 10 & $33.3 \%$ & & \\
\hline $\begin{array}{l}1-2 \text { million IDR } \\
\text { (76.97 - 153.93 USD) }\end{array}$ & 9 & $30.0 \%$ & 8 & $26.7 \%$ & & \\
\hline $\begin{array}{l}\text { 2-4 million IDR } \\
\text { (153.93 - } 307.87 \text { USD) }\end{array}$ & 5 & $16.7 \%$ & 7 & $23.3 \%$ & & \\
\hline $\begin{array}{l}>4 \text { million IDR } \\
\text { (> 307.87 USD) }\end{array}$ & 10 & $33.3 \%$ & 5 & $16.7 \%$ & & \\
\hline Occupation & & & & & $4.87^{\mathrm{c}}$ & .432 \\
\hline Entrepreneur & 10 & $33.3 \%$ & 10 & $33.3 \%$ & & \\
\hline Government employee & 4 & $13.3 \%$ & 3 & $10.0 \%$ & & \\
\hline Private sector employee & 4 & $13.3 \%$ & 2 & $6.7 \%$ & & \\
\hline Farmer & 0 & $0.0 \%$ & 1 & $3.3 \%$ & & \\
\hline Unemployed / retired & 12 & $40.0 \%$ & 14 & $46.7 \%$ & & \\
\hline Number of hospitalization & & & & & $8.74^{\mathrm{c}}$ & $.033^{*}$ \\
\hline 1 & 16 & $53.3 \%$ & 23 & $76.7 \%$ & & \\
\hline 2 & 6 & $20.0 \%$ & 6 & $20.0 \%$ & & \\
\hline 3 & 4 & $13.3 \%$ & 1 & $3.3 \%$ & & \\
\hline$>3$ & 4 & $13.3 \%$ & 0 & $0.0 \%$ & & \\
\hline Types of MI & & & & & $.11^{\mathrm{a}}$ & .739 \\
\hline STEMI & 25 & $83.3 \%$ & 24 & $80.0 \%$ & & \\
\hline NSTEMI & 5 & $16.7 \%$ & 6 & $20.0 \%$ & & \\
\hline MI Treatment & & & & & $1.93^{\mathrm{a}}$ & .165 \\
\hline Medication & 7 & $23.3 \%$ & 12 & $40.0 \%$ & & \\
\hline PCI & 23 & $76.7 \%$ & 18 & $60.0 \%$ & & \\
\hline
\end{tabular}

Table 1 presents that the demographic and health related characteristics of the patients in the control and the experimental group were not significantly different $(\mathrm{p}>.05)$, except for marital status and the number of hospitalizations. 


\subsection{The demographic characteristics of the patients' family members}

Table 2 shows that the demographic characteristics of the patients' family members in the control and the experimental group were not significantly different $(\mathrm{p}>.05)$. The majority of patients' family members $(93.3 \%)$ in the experimental group and $(96.7 \%)$ in the control group had no experience in taking care of patients with heart disease. The mean score of family member's self-efficacy in take care of the patient was $6.47(\mathrm{SD}=1.81)$ in the experimental group and $6.63(\mathrm{SD}=2.02)$ in the control group before receiving the intervention.

Table 2. The Differences of the Family Members Demographic Characteristics of the Experimental and the Control Groups $(\mathrm{N}=60)$

\begin{tabular}{|c|c|c|c|c|c|c|}
\hline \multirow[t]{2}{*}{ Characteristic } & \multicolumn{2}{|c|}{$\begin{array}{l}\text { Experimental Group } \\
(\mathrm{n}=30)\end{array}$} & \multicolumn{2}{|c|}{$\begin{array}{c}\text { Control Group } \\
(\mathrm{n}=30)\end{array}$} & \multirow{2}{*}{$\begin{array}{l}\text { Statistic } \\
\text { values }\end{array}$} & \multirow[t]{2}{*}{ p-value } \\
\hline & $\mathrm{n}$ & $\%$ & $\mathrm{n}$ & $\%$ & & \\
\hline Age (year) & \multicolumn{4}{|c|}{$(\operatorname{Min}-\operatorname{Max})=(18-73)$} & $.10^{\mathrm{b}}$ & .920 \\
\hline Gender & & & & & $.39^{\mathrm{d}}$ & .389 \\
\hline Male & 2 & $6.7 \%$ & 4 & $13.3 \%$ & & \\
\hline Female & 28 & $93.3 \%$ & 26 & $86.7 \%$ & & \\
\hline Educational Level & & & & & $2.32^{\mathrm{c}}$ & .678 \\
\hline No schooling & 0 & $0.0 \%$ & 1 & $3.3 \%$ & & \\
\hline Elementary school & 3 & $10.0 \%$ & 5 & $16.7 \%$ & & \\
\hline Junior high school & 6 & $20.0 \%$ & 5 & $16.7 \%$ & & \\
\hline High School & 14 & $46.7 \%$ & 14 & $46.7 \%$ & & \\
\hline College & 7 & $23.3 \%$ & 5 & $16.7 \%$ & & \\
\hline Family relationship & & & & & $2.35^{\mathrm{c}}$ & .308 \\
\hline Wife & 24 & $80.0 \%$ & 20 & $66.7 \%$ & & \\
\hline Husband & 0 & $0.0 \%$ & 1 & $3.3 \%$ & & \\
\hline Child & 6 & $20.0 \%$ & 9 & $30.0 \%$ & & \\
\hline Family history & & & & & $.00^{\mathrm{a}}$ & 1.000 \\
\hline Yes & 16 & $53.3 \%$ & 16 & $53.3 \%$ & & \\
\hline No & 14 & $46.7 \%$ & 14 & $46.7 \%$ & & \\
\hline Family experience & & & & & $1.00^{\mathrm{d}}$ & .554 \\
\hline Yes & 2 & $6.7 \%$ & 1 & $3.3 \%$ & & \\
\hline No & 28 & $93.3 \%$ & 29 & $96.7 \%$ & & \\
\hline Family self-efficacy & Mean $=6.47$ & $\mathrm{SD}=1.81$ & Mean $=$ & $=2.02$ & $-.34^{\mathrm{b}}$ & .738 \\
\hline
\end{tabular}

3.3. The effect of the family-based self-efficacy enhancing cardiac rehabilitation program on selfefficacy in cardiac health behaviors before and after intervention for the experimental group

Table 3 presents that the mean score of self-efficacy of the patients in the experimental group was significantly better $(\mathrm{t}=-3.83, \mathrm{p}<.05)$ after receiving the intervention $(\mathrm{M}=43.43, \mathrm{SD}=3.09)$ than before receiving the intervention $(\mathrm{M}=35.77, \mathrm{SD}=5.94)$. The subscales of self-efficacy of patients in the experimental group after receiving the intervention were also significantly better than before receiving the intervention $(\mathrm{p}<.05)$. These subscales included medication adherence efficacy, exercise efficacy, stress management efficacy, dietary efficacy, and smoking cessation efficacy.

Table 3. Comparison of the Self-efficacy Scores Before and After Intervention for the Experimental Group using Paired T-test $(\mathrm{N}=30)$

\begin{tabular}{lcccccr}
\hline \multirow{2}{*}{ Self-efficacy } & \multicolumn{2}{c}{ Before intervention } & \multicolumn{2}{c}{ After intervention } & \multirow{2}{*}{$\mathrm{t}$} & \multirow{2}{*}{$\mathrm{p}$-value } \\
\cline { 2 - 5 } & $\mathrm{M}$ & $\mathrm{SD}$ & $\mathrm{M}$ & $\mathrm{SD}$ & & \\
\cline { 2 - 5 } Total Self-efficacy & 35.77 & 5.94 & 43.43 & 3.09 & -3.83 & .012 \\
Medication adherence efficacy & 7.70 & 2.28 & 9.20 & 0.85 & -3.83 & .009 \\
Exercise efficacy & 6.37 & 2.40 & 8.40 & 1.25 & -5.60 & .001 \\
Stress management efficacy & 6.37 & 1.97 & 7.80 & 1.54 & -4.29 & .007 \\
Dietary efficacy & 6.63 & 2.11 & 8.37 & 1.35 & -5.12 & .008 \\
Smoking cessation efficacy & 8.70 & 2.09 & 9.67 & 0.76 & -7.89 & .000 \\
\hline
\end{tabular}


3.4. The effect of the family-based self-efficacy enhancing cardiac rehabilitation program on selfefficacy in cardiac health behaviors in the experimental group and the control group

Table 4 describes that the mean scores of self-efficacy in cardiac health behaviors before receiving the intervention were not significantly better $(\mathrm{p}>.05)$ in the experimental group $(\mathrm{M}=35.77, \mathrm{SD}=5.94)$ than those in the control group $(M=33.57, \mathrm{SD}=9.44)$. After receiving the intervention, the mean scores of selfefficacy in cardiac health behaviors were significantly better $(t=6.03, p<.05)$ in the experimental group (M $=43.43, \mathrm{SD}=3.09)$ than those in the control group $(\mathrm{M}=35.17, \mathrm{SD}=6.85)$.

Table 4. Comparison of the Self-efficacy in the Experimental and the Control Groups using Independent T-test $(\mathrm{N}=60)$

\begin{tabular}{|c|c|c|c|c|c|c|}
\hline \multirow[t]{2}{*}{ Self-efficacy } & \multicolumn{2}{|c|}{$\begin{array}{l}\text { Experimental Group } \\
(\mathrm{n}=30)\end{array}$} & \multicolumn{2}{|c|}{$\begin{array}{l}\text { Control Group } \\
(\mathrm{n}=30)\end{array}$} & \multirow[t]{2}{*}{$\mathrm{t}$} & \multirow[t]{2}{*}{ p-value } \\
\hline & $\mathrm{M}$ & SD & $\mathrm{M}$ & SD & & \\
\hline \multicolumn{7}{|l|}{ Before intervention } \\
\hline Total Self-efficacy & 35.77 & 5.94 & 33.57 & 9.44 & 1.08 & .285 \\
\hline Medication adherence efficacy & 7.70 & 2.28 & 6.90 & 2.43 & 1.32 & .193 \\
\hline Exercise efficacy & 6.37 & 2.39 & 5.77 & 2.88 & 0.88 & .384 \\
\hline Stress management efficacy & 6.37 & 1.98 & 6.13 & 2.14 & 0.44 & .663 \\
\hline Dietary efficacy & 6.63 & 2.11 & 6.47 & 1.79 & 0.33 & .743 \\
\hline Smoking cessation efficacy & 8.70 & 2.09 & 8.30 & 2.89 & 0.61 & .541 \\
\hline \multicolumn{7}{|l|}{ After intervention } \\
\hline Total Self-efficacy & 43.43 & 3.09 & 35.17 & 6.85 & 6.03 & .000 \\
\hline Medication adherence efficacy & 9.20 & 0.85 & 7.43 & 1.59 & 5.37 & .000 \\
\hline Exercise efficacy & 8.40 & 1.25 & 6.23 & 2.59 & 4.12 & .000 \\
\hline Stress management efficacy & 7.80 & 1.54 & 6.47 & 1.57 & 3.32 & .002 \\
\hline Dietary efficacy & 8.37 & 1.35 & 6.20 & 1.52 & 5.84 & .000 \\
\hline Smoking cessation efficacy & 9.67 & 0.76 & 8.83 & 1.93 & 2.20 & .032 \\
\hline
\end{tabular}

3.5. The effect of the family-based self-efficacy enhancing cardiac rehabilitation program on health behaviors before and after intervention for the experimental group

Table 5 shows that the mean scores of health behaviors of the patients in the experimental group after receiving the intervention were significantly better than before receiving the intervention $(\mathrm{p}<.05)$. These health behaviors included medication adherence, exercise behaviors, stress management, and smoking cessation. In contrast, dietary behavior of the patients in the experimental group after receiving the intervention was not significantly better $(\mathrm{t}=-1.24, \mathrm{p}>.05)$ than before receiving the intervention.

Table 5. Comparison of the Health Behaviors Scores Before and After Intervention for the Experimental Group using Paired T-test $(\mathrm{N}=30)$

\begin{tabular}{|c|c|c|c|c|c|c|}
\hline \multirow{2}{*}{ Health behaviors } & \multicolumn{2}{|c|}{ Before intervention } & \multicolumn{2}{|c|}{ After intervention } & \multirow{2}{*}{$\mathrm{t}$} & \multirow{2}{*}{$\mathrm{p}$-value } \\
\hline & $\mathrm{M}$ & SD & $\mathrm{M}$ & SD & & \\
\hline Total health behaviors & 95.13 & 10.75 & 118.47 & 5.72 & -11.77 & .000 \\
\hline Medication adherence & 21.73 & 3.11 & 23.07 & 1.39 & -2.60 & .014 \\
\hline Exercise behaviors & 22.30 & 4.76 & 25.07 & 4.86 & -3.31 & .003 \\
\hline Dietary behaviors & 25.63 & 3.47 & 26.63 & 2.67 & -1.24 & .224 \\
\hline Stress management & 18.17 & 2.72 & 20.27 & 1.99 & -3.37 & .002 \\
\hline Smoking cessation & 20.20 & 5.95 & 22.87 & 1.25 & -2.61 & .014 \\
\hline
\end{tabular}


3.6. The effect of the family-based self-efficacy enhancing cardiac rehabilitation program on health behaviors in the experimental group and the control group

Table 6 presents that the mean scores of health behaviors before receiving the intervention were not significantly better in the experimental group than that in the control group ( $p>.05)$. After receiving the intervention, the mean scores of health behaviors in the experimental group were significantly better than that in the control group $(\mathrm{p}<.05)$. These health behaviors included medication adherence, exercise behaviors, dietary behaviors, stress management, and smoking cessation.

Table 6. Comparison of the Health Behaviors in the Experimental and the Control Groups using Independent t-test $(\mathrm{N}=60)$

\begin{tabular}{|c|c|c|c|c|c|c|}
\hline \multirow[t]{2}{*}{ Health Behaviors } & \multicolumn{2}{|c|}{$\begin{array}{l}\text { Experimental Group } \\
(\mathrm{n}=30)\end{array}$} & \multicolumn{2}{|c|}{$\begin{array}{l}\text { Control Group } \\
(\mathrm{n}=30)\end{array}$} & \multirow[t]{2}{*}{$\mathrm{t}$} & \multirow[t]{2}{*}{ p-value } \\
\hline & $\mathrm{M}$ & SD & $\mathrm{M}$ & SD & & \\
\hline \multicolumn{7}{|l|}{ Before intervention Group } \\
\hline Total health behaviors & 95.13 & 10.75 & 93.70 & 14.06 & 0.44 & .659 \\
\hline Medication adherence & 21.73 & 3.11 & 19.93 & 2.73 & 2.38 & .020 \\
\hline Exercise behaviors & 22.30 & 4.76 & 17.90 & 4.19 & 3.79 & .000 \\
\hline Dietary behaviors & 25.63 & 3.47 & 18.97 & 4.67 & 6.27 & .000 \\
\hline Stress management & 18.17 & 2.72 & 17.60 & 3.26 & 0.73 & .468 \\
\hline Smoking cessation & 20.20 & 5.95 & 19.07 & 5.53 & 0.76 & .448 \\
\hline \multicolumn{7}{|l|}{ After intervention } \\
\hline Total health behaviors & 118.47 & 5.72 & 97.83 & 10.97 & 9.13 & .000 \\
\hline Medication adherence & 23.07 & 1.39 & 19.83 & 2.57 & 6.06 & .000 \\
\hline Exercise behaviors & 25.07 & 4.86 & 18.97 & 4.67 & 4.96 & .000 \\
\hline Dietary behaviors & 26.63 & 2.67 & 22.33 & 3.01 & 5.85 & .000 \\
\hline Stress management & 20.27 & 1.99 & 17.27 & 3.14 & 4.41 & .000 \\
\hline Smoking cessation & 22.87 & 1.25 & 19.43 & 4.83 & 3.77 & .000 \\
\hline
\end{tabular}

3.7. The effect of the family-based self-efficacy enhancing cardiac rehabilitation program on the clinical outcomes before and after intervention for the experimental group

Table 7 describes that the clinical outcomes of the patients in the experimental group after receiving the intervention such as fasting blood glucose, total cholesterol, LDL, triglyceride, and BMI were significantly better than before receiving the intervention $(\mathrm{p}<.05)$. In contrast, the mean scores of HDL, systolic blood pressure, and diastolic blood pressure of the patients in the experimental group after receiving the intervention were not significantly better than before receiving the intervention $(p>.05)$.

Table 7. Comparison of the Clinical Outcomes Scores Before and After Intervention of the Experimental Group using Paired T-Test $(\mathrm{N}=30)$

\begin{tabular}{|c|c|c|c|c|c|c|}
\hline \multirow{2}{*}{ Clinical Outcomes } & \multicolumn{2}{|c|}{ Before intervention } & \multicolumn{2}{|c|}{ After intervention } & \multirow{2}{*}{$\mathrm{t}$} & \multirow{2}{*}{ p-value } \\
\hline & $\mathrm{M}$ & SD & $\mathrm{M}$ & SD & & \\
\hline Systolic & 128.87 & 29.98 & 120.33 & 13.77 & 1.83 & .078 \\
\hline Diastolic & 72.13 & 10.90 & 74.63 & 6.79 & -1.12 & .273 \\
\hline Fasting blood glucose & 120.83 & 42.58 & 98.10 & 14.74 & 3.01 & .005 \\
\hline Total Cholesterol & 190.03 & 40.18 & 149.87 & 26.34 & 5.40 & .000 \\
\hline LDL & 124.93 & 45.28 & 90.00 & 24.58 & 4.76 & .000 \\
\hline HDL & 43.60 & 12.18 & 42.77 & 8.99 & 0.32 & .749 \\
\hline Triglyceride & 155.37 & 105.29 & 113.37 & 26.13 & 2.41 & .022 \\
\hline BMI & 24.40 & 2.57 & 24.05 & 2.53 & 2.91 & .007 \\
\hline
\end{tabular}

3.8. The effect of the family-based self-efficacy enhancing cardiac rehabilitation program on the clinical outcomes in the experimental group and the control group

Table 8 shows that the mean scores of the clinical outcomes in the experimental group and the control group before receiving the intervention were not significantly different $(p>.05)$. After receiving the intervention, the mean scores of the clinical outcomes of the experimental group were significantly better than in the control group ( $\mathrm{p}<.05$ ), especially for total cholesterol, LDL, and triglyceride. In contrast, the mean score of BP, fasting blood glucose, HDL and BMI in the experimental group after receiving the intervention were not significantly better than the control group $(\mathrm{p}>.05)$. 
Table 4. Comparison of the Clinical Outcomes in the Experimental and the Control Groups using Independent T-test $(\mathrm{N}=60)$

\begin{tabular}{|c|c|c|c|c|c|c|}
\hline \multirow[t]{2}{*}{ Clinical Outcomes } & \multicolumn{2}{|c|}{$\begin{array}{l}\text { Experimental Group } \\
(\mathrm{n}=30)\end{array}$} & \multicolumn{2}{|c|}{$\begin{array}{l}\text { Control Group } \\
(\mathrm{n}=30)\end{array}$} & \multirow[t]{2}{*}{$\mathrm{t}$} & \multirow[t]{2}{*}{ p-value } \\
\hline & $\mathrm{M}$ & SD & $\mathrm{M}$ & SD & & \\
\hline \multicolumn{7}{|l|}{ Before intervention } \\
\hline Systolic & 128.87 & 29.98 & 121.93 & 21.83 & 1.02 & .310 \\
\hline Diastolic & 72.13 & 10.90 & 71.40 & 11.38 & 0.25 & .800 \\
\hline Fasting blood glucose & 120.83 & 42.58 & 110.70 & 19.95 & 1.18 & .243 \\
\hline Total Cholesterol & 190.03 & 40.18 & 191.23 & 38.11 & -0.12 & .906 \\
\hline LDL & 124.93 & 45.28 & 131.33 & 35.79 & -0.61 & .546 \\
\hline HDL & 43.60 & 12.18 & 39.90 & 9.55 & 1.31 & .196 \\
\hline Triglyceride & 155.37 & 105.29 & 171.83 & 69.70 & -0.71 & .478 \\
\hline BMI & 24.40 & 2.57 & 24.39 & 3.70 & 0.01 & .988 \\
\hline \multicolumn{7}{|l|}{ After intervention } \\
\hline Systolic & 120.33 & 13.77 & 126.00 & 19.05 & -1.32 & .192 \\
\hline Diastolic & 74.63 & 6.79 & 76.67 & 9.59 & -0.95 & .347 \\
\hline Fasting blood glucose & 98.10 & 14.74 & 106.50 & 32.27 & -1.29 & .200 \\
\hline Total Cholesterol & 149.87 & 26.34 & 185.87 & 33.48 & -4.63 & .000 \\
\hline LDL & 90.00 & 24.58 & 123.67 & 29.31 & -4.82 & .000 \\
\hline HDL & 42.77 & 8.99 & 46.77 & 15.29 & -1.23 & .222 \\
\hline Triglyceride & 113.37 & 26.13 & 166.40 & 71.67 & -3.81 & .000 \\
\hline BMI & 24.05 & 2.53 & 24.22 & 3.84 & -0.21 & .834 \\
\hline
\end{tabular}

\section{DISCUSSION}

\subsection{Self-efficacy in cardiac health behaviors.}

Self-efficacy of MI patients in the experimental group after receiving the intervention was significantly better than before receiving the intervention (Table 3). The positive outcomes on self-efficacy after the patients had received the intervention were related to four sources of self-efficacy that were used to develop the program including mastery experience, vicarious experience, verbal persuasion, and physiological and emotional responses. In this study, mastery experience was facilitated through involving the patients in exercise and practice to measure their pulse rates before and after exercise. Mastery experience can minimize the perception of barriers, increase tolerance, give a sense of accomplishment and build confidence in the ability to perform healthy behaviors [21].

The vicarious experience was provided through a video about MI patients who have succeeded in performing health behaviors and successful of family member in providing support for patient to perform health behaviors. The models in the video had the same characteristics as most of the patients in this study (gender, age, medical condition, and therapy) to represent the patients' condition. Verbal persuasion was utilized by providing educational and sharing sessions involving the patient's family. Hiltunen, Winder, Rait, Buselli, and $\mathrm{Al}$ [22] also reported that encouragement and patient education was effective to promote selfefficacy of health behavior after a cardiac event. The physiological and emotional responses were provided with information about normal sensations and any possible physical discomforts. They were also taught the strategies to reduce any feeling of discomfort to encourage a more positive emotional state.

\subsection{Health behaviors}

The health behaviors of the experimental group after receiving the intervention were significantly better than before receiving the intervention (Table 5). In addition, the health behaviors after receiving the intervention in the experimental group were significantly better than that of the control group (table 6). It is possible that the results were influenced by features of the program that included: (1) developing based on sources of self-efficacy; (2) involving family members to promote health behaviors; (3) initiating during the inpatient phase when patients perceived a high health risk after a cardiac event and are more motivated to learn; (4) continuing with a phone follow-up session after discharge to monitor and provide reinforcement on health behaviors.

In this study, the increasing self-efficacy in cardiac health behaviors score in MI patients was immediately followed by an increase in the health behaviors scores. The result was consistent with previous research that reported people with high self-efficacy are more likely to adopt advantageous health behaviors than are those with low self-efficacy [23]. In the study of Kang et al [8] cardiac self-efficacy showed the greatest effect on health behaviors as well. Previous studies strongly concurred with the result of the present study that revealed self-efficacy can determine health behaviors.

Regarding medication adherence, the results were congruent with previous studies that reported better results in medication adherence after the patients had participated in cardiac rehabilitation [11],[24]. Family involvement in the program was essential for the success of medication adherence to provide 
instrumental and informational support for promoting medication adherence. In performing exercise behavior, some patients still reported barriers in performing exercise such as symptoms of heart disease, weather, and lack of time. However, family involvement in exercise regularly helped the patients to be more motivated to perform exercise behavior, adjust to the barriers and have their own strategies to overcome these barriers.

Regarding dietary behavior, a previous study also reported similar results in that dietary behavior was not significantly change and stable over a long period of time [25]. Dietary behavior was reported as the common barrier experienced by the patients due to individual dietary habits that related to culture which need to be adapted for change. Approximately $65 \%$ of the Indonesian population tends to consume diet with sweet food and $25 \%$ of the population consumes high salty food [26]. Therefore, the eating culture in a family should be adjusted to meet individualized culturally appropriate dietary modifications [27] in order to support dietary behavior.

The program has significant effect on stress management that were associated with the family involvement in providing emotional support. Previous research reported that emotional or psychological stress potentially contributes to poorer adherence to other health behaviors after MI [28]. Smoking cessation behavior in the present study was significantly changed. The reduction in number of smokers in this study was advantageous in reducing the risk of MI [29].

\subsection{Clinical outcomes.}

In the present study, the effectiveness of the program on blood pressure (BP) was not significant. Previous studies revealed that BP did not fall significantly when patients take less than $80 \%$ of their prescribed medication. Somehow, in the present study the patients reported having significantly better medication adherence behavior. Hence, the results in the present study revealed as the impact of normal level of BP in most of the patients at baseline. In the present study, total cholesterol, LDL, and triglyceride of the experimental group after receiving the intervention were significantly better than before receiving the intervention and better than that of the control group. These findings are congruent with the results of the study conducted by Jiang et al [24] which reported total cholesterol, LDL, and triglycerides showed significantly greater reduction in the experimental group.

Unfortunately, the effect of the program did not show significant results on HDL. A similar phenomenon was also observed from the study conducted by Kang et al [8] in that HDL levels were not statistically significant between two groups related to the lower efficacy of lipid-lowering drugs in influencing HDL. Patients in the present study were taking lipid-lowering drugs at hospital discharge. The results could be influenced by the effect of types of lipid-lowering drugs including generic and branded drugs that were not controlled. However, the levels of cholesterol were not affected by the types of lipid-lowering drugs if the patients not adhere to the medication. Accordingly, the significant changes of medication adherence efficacy and medication adherence behavior score of the patients in the experimental group after receiving the intervention also contributed on the better level of cholesterol. Moreover, the program involved the family to support the patients on behavior change. Additionally, in this study, the efficacy of drugs on HDL and types of the lipid-lowering drugs need to be investigated more to prove the true effect of the program on the clinical outcomes.

The result shows that $63.3 \%$ of the patients had a normal score of BMI. In the present study, BMI of the experimental group after receiving the intervention was not significantly better than the control group. The finding was similar with the report by Jiang et al [24]. The result might be related with the normal score of BMI in most of patients at baseline, and also the effect of insignificant better results on dietary behavior. Patients may control their diet such as restricting their fat and cholesterol intake which appears to have a significant effect on cholesterol levels. However, the patients showed a lack of attention in restricting their carbohydrate intake or some even ate more. In the present study, fasting blood glucose of the intervention group was significantly better after receiving the intervention but not significantly better than the control group. It may be related to the eating culture of Indonesian people where rice is the daily main food and rice create high carbohydrate and glucose.

\section{CONCLUSIONS}

The findings of this study clearly indicate the positive effect of family based self-efficacy enhancing cardiac rehabilitation program on self-efficacy, health behaviors, and some clinical outcomes in MI patients such as fasting blood glucose, total cholesterol, LDL, triglyceride, and BMI except for systolic and diastolic blood pressure, and HDL levels. This study indicated that encouraging MI patients and family members to adopt CR program and continue implement in their daily life is beneficial for MI patients. Health care providers should concern more in promoting the CR programs. 


\section{ACKNOWLEDGEMENTS}

This study was supported by the research fund from the Directorat General of Higher Education, Ministry of National Education of Indonesia, and Graduate School of Prince of Songkla University, Thailand.

\section{REFERENCES}

[1] Thygesen K., Alpert JS., White HD., "Universal definition of Myocardial Infarction”, Journal of the American College of Cardiology, vol. 50, 2007.

[2] Ministry of Health of the Republic of Indonesia, "Profil kesehatan Indonesia tahun 2013 [ Indonesia health profile in 2013]", 2014. Retrieved from: http://www.depkes.go.id/resources/download/pusdatin/profil-kesehatanindonesia/profil-kesehatan-indonesia-2013.pdf.

[3] Kikkert WJ., Hoebers LP., Damman P., Lieve KV., Claessen BE., Vis MM., Henriques JP., "Recurrent myocardial infarction after primary percutaneous coronary intervention for ST-segment elevation myocardial infarction", American Journal of Cardiology, vol. 113, pp. 229-35, 2014.

[4] Murray J., Craigs CL., Hill KM., Honey S., House A., "A systematic review of patient reported factors associated with uptake and completion of cardiovascular lifestyle behaviour change", BMC Cardiovascular Disorders, vol. 12, pp. 120, 2012.

[5] Radi B., Joesoef A., Kusmana D., "Rehabilitasi Kardiovaskular Di Indonesia [cardiac rehabilitation in Indoonesia]", Jurnal Kardiologi Indonesia, vol. 30, pp. 43-5, 2009.

[6] Majid A., "Analisis faktor-faktor yang berhubungan dengan kejadian rawat inap ulang pasien gagal jantung kongestif di rumah sakit yogyakarta tahun 2010 [Analysis of factors associated with the incidence of rehospotalization in congestive heart failure patients in hospital Yogyakarta in 2010]", Master's thesis, 2010. Retrieved from http://www.lontar.ui.ac.id/opac/ui/.

[7] Balady GJ., Williams MA., Ades PA., Bittner V., Comoss P., Foody JM., "Southard D. Core components of cardiac rehabilitation/secondary prevention programs", Circulation, vol. 115, pp. 2675-82, 2007.

[8] Kang Y., Yang IS., Kim N., "Correlates of Health Behaviors in Patients With Coronary Artery Disease", Asian Nursing Research, vol/issue: 4(1), pp. 45-55, 2010.

[9] Bandura A., "Self-Efficacy: The exercise of control", New York, NY, W.H. Freeman, 1997.

[10] Lau-Walker M., "Predicting self-efficacy using illness perception components: A patient survey", British Journal of Health Psychology, vol. 11, pp. 643-61, 2006.

[11] Ahyana, "The effect of self-efficacy enhancing cardiac rehabilitation program on health behaviors among patients with Myocardial Infarction in Aceh, Indonesia", Master's thesis, Prince of Songkla University, Thailand, 2013.

[12] Carroll DL., Rankin SH., Cooper BA., "The effects of a collaborative peer advisor/advanced practice nurse intervention: Cardiac rehabilitation participation and rehospitalization in older adults after a cardiac event", Journal of Cardiovascular Nursing, vol. 22, pp. 313-19, 2007.

[13] Song KJ., "The effects of self-efficacy promoting cardiac rehabilitation program on self-efficacy, health behavior, and quality of life", Taehan Kanho Hakhoe Chi, vol. 33, pp. 510-18, 2003.

[14] American Heart Association, "Getting healthy", 2014. Retrieved from http://www. heart.org/heartorg/gettinghealthy/gettinghealthy_ucm_001078_subhomepage.jsp.

[15] Luszczynska A., Schwarzer R., "Multidimensional health locus of control: comments on the construct and its measurement", J Health Psychol, vol/issue: 10(5), pp. 633-42, 2005.

[16] Campbell TL., "The effectiveness of family interventions for physical disorders", Journal of Marital and Family Therapy, vol. 29, pp. 263-81, 2003.

[17] Hariadi, A., "Hubungan obesitas dengan beberapa faktor risiko penyakit jantung koroner di laboratorium klinik Prodia makassar tahun 2005 [Correlation between obesity and multiple risk factors of coronary heart disease in Prodia clinical laboratories makasar in 2005]", pp. 1-14, 2005.

[18] Savage PD., Sanderson BK., Brown TM., Berra K., Ades PA., "Clinical research in cardiac rehabilitation and secondary prevention: looking back and moving forward", Journal of Cardiopulmonary Rehabilitation and Prevention, vol. 31, pp. 333-41, 2011.

[19] Kang M., Ragan BG., Park J., "Issues in outcomes research: an overview of randomization techniques for clinical trials", Journal of Athletic Training (National Athletic Trainers' Association), vol/issue: 43(2), pp. 215-21, 2008.

[20] Bandura A., "Guide for constructing self-efficacy scales", In D. Pajares, F., Urdan, T. (Eds.), "Self-efficacy beliefs of adolescents: Information age publishing", Greenwich, CT., pp. 307-37, 2006.

[21] Du H., Everett B., Newton P., Salamonson Y., Davidson P., "Self-efficacy: a useful construct to promote exercise in people with stable chronic heart failure", Journal of Clinical Nursing, vol/issue: 21(3/4), pp. 301-10, 2012.

[22] Hiltunen EF., Winder PA., Rait MA., Buselli EF., Al E., "Implementation of efficacy enhancement nursing interventions with cardiac elders", Rehabilitation Nursing, vol/issue: 30(6), pp. 221-9, 2005.

[23] Brink E., Alsen P., Herlitz J., Kjellgren K., Cliffordson C., "General self-efficacy and health-related quality of life after myocardial infarction", Psychol Health Med, vol/issue: 17(3), pp. 346-55, 2012.

[24] Jiang X., Sit JW., Wong TKS., "A nurse-led cardiac rehabilitation programme improves health behaviours and cardiac physiological risk parameters: evidence from Chengdu, China", Journal of Clinical Nursing, vol/issue: 16(10), pp. 1886-97, 2007.

[25] Lindsay S., Smith S., Bellaby P., Baker R., "The health impact of an online heart disease support group: a comparison of moderated versus unmoderated support", Health Education Research, vol. 24, pp. 646-54, 2009. 
[26] Usfar AA., Fahmida U., "Do Indonesians follow its Dietary Guidelines? - evidence related to food consumption, healthy lifestyle, and nutritional status within the period 2000-2010", Asia Pacific Journal of Clinical Nutrition, vol/issue: 20(3), pp. 484-94, 2011.

[27] Eshah NF., Bond AE., "Cardiac rehabilitation programme for coronary heart disease patients: an integrative literature review", International Journal of Nursing Practice, vol/issue: 15(3), pp. 131-9, 2009.

[28] Benyamini Y., Roziner I., Goldbourt U., Drory Y., Gerber Y., "Depression and anxiety following myocardial infarction and their inverse associations with future health behaviors and quality of life", Annals of Behavioral Medicine, vol/issue: 46(3), pp. 310-21, 2013.

[29] Go AS., Mozaffarian D., Roger VL., Benjamin EJ., Berry JD., Blaha MJ., "Turner MB. Heart disease and stroke statistics-2014 Update: A report from the American Heart Association”, Circulation, vol. 129, pp. e28-e292, 2014. 